\title{
Predictors of Negative Pressure Ventilation Response in Pediatric Acute Respiratory Failure
}

\author{
Crystal A Nunez and Amanda B Hassinger
}

\begin{abstract}
BACKGROUND: Use of negative pressure ventilation is neither well described nor widespread in pediatric critical care; existing data are from small, specialized populations. We sought to describe a general population of critically ill subjects with acute respiratory failure supported with negative pressure ventilation to find predictors of response or failure. METHODS: We conducted a retrospective cohort study of subjects $0-18$ y old admitted to a single (non-cardiac) pediatric ICU who received acute respiratory failure support via negative pressure ventilation from May 2015 through May 2016. RESULTS: In 118 subjects, the most common causes of acute respiratory failure were viral bronchiolitis $(86.4 \%)$ and pneumonia (15.3\%). A majority of subjects $(68.6 \%)$ stabilized with negative pressure ventilation and did not need a change of respiratory support; in those who failed with negative pressure ventilation, median time to respiratory support change was $5.1 \mathrm{~h}$ (interquartile range 1.9-11.0). Subjects stabilized with negative pressure ventilation did not differ from those needing a change of respiratory support in terms of age, comorbidities, or $\mathrm{F}_{\mathrm{IO}_{2}}$ at initiation of ventilation. Compared to those who did not respond to negative pressure ventilation, mean $\mathrm{S}_{\mathrm{pO}_{2}} / \mathrm{F}_{\mathrm{IO}_{2}}$ was higher at $1 \mathrm{~h}$ after start of negative pressure ventilation (218.8 vs 131.7) in those who did respond. Subjects with $\mathrm{S}_{\mathrm{pO}_{2}} / \mathrm{F}_{\mathrm{IO}_{2}}<192$ after $1 \mathrm{~h}$ on negative pressure ventilation support had 5-fold higher odds of needing a respiratory support change (odds ratio 5.143, 95\% CI 1.17-22.7, $P=.031)$. Analysis of $\mathrm{S}_{\mathrm{pO}_{2}} / \mathrm{F}_{\mathrm{IO}_{2}}$ was limited by $81.3 \%(96 / 118)$ of subjects who had an $\mathrm{S}_{\mathrm{pO}_{2}}>97 \%$ at $1 \mathrm{~h}$ after the start of negative pressure ventilation. CONCLUSIONS: Negative pressure ventilation successfully supported $69 \%$ of pediatric subjects with all-cause acute respiratory failure. Oxygen requirement was lower in subjects who were responsive to negative pressure ventilation within $1 \mathrm{~h}$ of initiation. Standardized negative pressure ventilation protocols should include weaning of supplemental oxygen to determine responsiveness. Key words: respiratory failure; pediatrics; negative pressure ventilation; biphasic cuirass ventilator; artificial respiration. [Respir Care 2020;65(1):91-98. (C) 2020 Daedalus Enterprises]
\end{abstract}

\section{Introduction}

Negative pressure ventilation, a mode of noninvasive mechanical ventilation (NIV), applies sub-atmospheric pressures to the chest to augment the natural intrathoracic

\footnotetext{
Dr Nunez is affiliated with the Department of Pediatrics, University of Buffalo, Jacobs School of Medicine and Biomedical Sciences, Buffalo, New York. Dr Hassinger is affiliated with the Division of Pediatric Critical Care, John R Oishei Children's Hospital, Buffalo, New York.

A version of this article was presented as a Research Snapshot at the 47th Critical Care Congress, held February 25-28, 2018, in San Antonio, Texas.
}

The authors have disclosed no conflicts of interest. pressure generated during spontaneous breathing. ${ }^{1}$ Modern negative pressure ventilation devices (eg, the biphasic cuirass ventilator) are smaller, less obstructive to clinical assessments and care, and less detrimental to hemodynamics than the original negative pressure ventilator, the iron lung.

Negative pressure ventilators, such as the biphasic cuirass ventilator, apply negative pressure onto the chest wall

\footnotetext{
Correspondence: Amanda B Hassinger MD MSc, John R Oishei Children's Hospital, Division of Pediatric Critical Care, 1001 Ellicott St, Buffalo, New York 14203. E-mail: ahassinger@upa.chob.edu.
}

DOI: $10.4187 /$ respcare. 07020 
to increase transpleural pressure and recruit areas of atelectasis while improving preload to the heart. ${ }^{2}$ In neonatal models, this led to dilation of the pulmonary capillaries and improved ventilation-perfusion matching. ${ }^{3}$ The biphasic cuirass ventilator can also apply positive pressure onto the chest wall to augment lung recoil and assist exhalation. This active exhalation is unique to the biphasic cuirass ventilator when compared to other forms of invasive or NIV currently in use.

Early studies found that the biphasic cuirass ventilator decreased $\mathrm{F}_{\mathrm{IO}_{2}}$ requirements and increased $\mathrm{P}_{\mathrm{CO}_{2}}$ clearance within hours, and its use was associated with lower likelihood of intubation in small pediatric populations. ${ }^{2,4}$ In the largest pediatric negative pressure ventilation study to date, $70 \%$ of 233 critically ill subjects treated with a biphasic cuirass ventilator in a single pediatric ICU had resolution of acute respiratory failure with negative pressure ventilation with a $3 \%$ complication rate. ${ }^{5}$

As proven in other forms of NIV, ways to detect treatment response are crucial before widespread application of negative pressure ventilation in critically ill patients can be recommended. ${ }^{6}$ For example, adults using bilevel positive airway pressure intubated within $12 \mathrm{~h}$ had lower hospital mortality than those whose intubation was delayed past that point. ${ }^{7}$ Noninvasive measures such as $\mathrm{S}_{\mathrm{pO}_{2}} / \mathrm{F}_{\mathrm{IO}_{2}}$ have been successful in other populations in predicting NIV failure. $^{8}$

After more than 5 years of negative pressure ventilation use in our center, the biphasic cuirass ventilator is the most commonly used NIV device for pediatric acute respiratory failure. This robust, single-center experience provides an opportunity for research to inform other centers and protocol development. We performed this study to determine if early objective variables predicted response to negative pressure ventilation support. In addition, negative pressure ventilation use is not standardized in our institution because pediatric data to guide protocol development are lacking, specifically related to negative pressure ventilation settings and triggers for escalation or weaning. Therefore, this study also served to collect data for protocol development.

\section{Methods}

This retrospective cohort study included all patients $<19$ y of age admitted to Women and Children's Hospital, Buffalo, New York, a 20-bed pediatric ICU, with acute respiratory failure supported by negative pressure ventilation over 1 year (May 2015 to May 2016). The time frame was chosen to follow a previous cohort study as a validation dataset for a model to predict intubation. ${ }^{5}$ The only exclusion criterion was negative pressure ventilation use for chest physiotherapy only. The Institutional Review

\section{QUICK LOOK}

\section{Current knowledge}

Negative pressure ventilation provides respiratory support by augmenting the strength of the chest wall. Newer devices are available but are not used widely in pediatric critical care despite possible advantages over other noninvasive or invasive respiratory modalities.

\section{What this paper contributes to our knowledge}

In a single-center retrospective cohort study of a heterogeneous pediatric population with acute respiratory failure, a majority of children supported with negative pressure ventilation did not require intubation. Children who responded to negative pressure ventilation had lower oxygen requirements within the first hour compared to those who went onto more support; however, supplemental oxygen was not weaned routinely.

Board of the University at Buffalo approved this study with a waiver of consent.

\section{Respiratory Support Modalities}

Support for pediatric acute respiratory failure in our hospital during the study period began with high-flow nasal cannula (HFNC) in the emergency room or on the pediatric floor, and negative pressure ventilation was added if a subject were to clinically worsen. In all subjects, negative pressure ventilation was added to HFNC because negative pressure ventilation cannot deliver supplemental oxygen. Therefore, the data before initiation of negative pressure ventilation reflect the support provided with HFNC, whereas data after the addition of negative pressure ventilation reflect the effect of simultaneous support from negative pressure ventilation and HFNC. Because there was no protocol in place for weaning $\mathrm{F}_{\mathrm{IO}_{2}}$ while on HFNC in our institution, supplemental oxygen was titrated for low $\mathrm{S}_{\mathrm{pO}_{2}}$ values and often not weaned for excessive $\mathrm{S}_{\mathrm{pO}_{2}}$ values.

If a subject did not respond to negative pressure ventilation, other noninvasive modalities included nasal intermittent positive-pressure ventilation via a cannula, CPAP, or bilevel positive airway pressure via face mask or nasal interfaces. Subjects who failed negative pressure ventilation were placed more frequently on invasive mechanical ventilation instead of other NIV modalities.

\section{Negative Pressure Ventilation Strategies}

As previously mentioned, our institution did not have protocols dictating initiation, titration, or weaning of neg- 
ative pressure ventilation. The only existing institutional protocol during this study relating to negative pressure ventilation was scheduled assessment for skin breakdown at contact sites with the chest cuirass, performed every $4 \mathrm{~h}$ by a respiratory therapist and bedside nurse. Practices related to sedation, nutrition, laboratory studies, and the biphasic cuirass ventilator pressure settings were dictated by the discretion of pediatric critical care providers.

The biphasic cuirass ventilator used was the Hayek RTX respirator (Hayek Industries, London, United Kingdom). It applies a plastic shell, or cuirass, over the anterior chest wall from the sternal notch to the top of the abdomen and across to each mid-axillary line. The cuirass seals to the chest with a disposable foam rim. It has two available modes. Continuous negative extrathoracic pressure, the most common mode, is similar to CPAP, holding a continuous negative pressure against the chest wall, typically ranging from -8 to $-24 \mathrm{~cm} \mathrm{H}_{2} \mathrm{O}$. Control mode, which is akin to bilevel positive airway pressure, alternates negative pressure with positive pressure to force chest wall recoil, assisting in expiration. Control pressures are titrated in a 3:1 ratio typically (eg, -18 to $+6 \mathrm{~cm}_{2} \mathrm{O}$. Control mode delivers these pressures at a mandatory frequency set higher than the patient's spontaneous frequency and cannot synchronize with patient efforts. Because there is no interface with the mouth or nose, the biphasic cuirass ventilator cannot provide supplemental oxygen. HFNC was left in place and flows and $\mathrm{F}_{\mathrm{IO}_{2}}$ were not routinely weaned at the time of biphasic cuirass ventilator start.

\section{Data Collection}

Data collected include demographics, past medical history, admission diagnosis, comorbidities (ie, history of asthma or reactive airways, chronic lung disease, or prematurity using physician documentation of these conditions), vital signs, any available blood gas results, and level of respiratory support $1 \mathrm{~h}$ prior to and $1,4,8$, and $12 \mathrm{~h}$ after initiation of negative pressure ventilation. A previous study ${ }^{5}$ of negative pressure ventilation in similar pediatric populations reported median time to negative pressure ventilation failure of $\sim 7 \mathrm{~h}$; therefore, data collection regarding predictor variables stopped at $12 \mathrm{~h}$ after start of negative pressure ventilation. The primary outcome was negative pressure ventilation failure, which was defined as a change in respiratory support from negative pressure ventilation as determined by providers at the time. Secondary outcomes included previously reported and theoretical complications of negative pressure ventilation, such as hypothermia, skin breakdown, pneumothorax, gastroesophageal reflux, delayed enteral nutrition $(>48 \mathrm{~h})$, and agitation requiring sedation. ${ }^{5}$

\section{Statistical Analysis}

Appropriate measures of central tendency and comparison testing were used after Kolmogorov-Smirnov testing for normality of data. Regression modeling adjusted the measures of association for confounders and formed prediction models. Area under the receiver operating characteristic curves tested power to predict outcomes. Analyses were performed with SPSS 24 (IBM, Armonk, New York) with significance defined as $P<.05$.

\section{Results}

The study population consisted of 118 subjects aged 1-192 months who were supported with negative pressure ventilation for acute respiratory failure for any cause (Table 1). Eighty-one subjects $(68.6 \%)$ stabilized with negative pressure ventilation and did not need intubation or a change in respiratory support. In those who did not stabilize with negative pressure ventilation, failure occurred at a median of $5.1 \mathrm{~h}$ (IQR 1-3, 1.9-11.0); 30 subjects required intubation ( $81 \%$ of subjects were did not respond to negative pressure ventilation; $25.4 \%$ of all subjects). The remaining 7 subjects were rescued with bilevel positive airway pressure or a nasal cannula. The only differences in baseline characteristics of subjects responsive to negative pressure ventilation compared to those who required a different mode of ventilation were proportion with upper airway pathology and PRISM score. Having a history of upper airway pathology or narrowing increased the odds of negative pressure ventilation failure 6-fold (odds ratio $6.016,95 \%$ CI $1.109-32.629, P=.038)$. There were no reported cases of intrathoracic airway narrowing, such as tracheo- or bronchomalacia.

\section{Predictor Variables for Negative Pressure Ventilation Response}

There were no differences in the baseline clinical variables between subjects who responded and those who did not respond to negative pressure ventilation, with the exception of initial venous $\mathrm{pH}$ (Table 1).

Within an hour of initiation of negative pressure ventilation, mean $\mathrm{F}_{\mathrm{IO}_{2}}$ was lower in those responsive to this ventilation than those who required escalation $(0.47 \pm 0.18$ vs $0.56 \pm 0.26, P=.02$ ), and this value remained lower at 4,8 , and $12 \mathrm{~h}$ (Fig. 1). Having a $\mathrm{F}_{\mathrm{IO}_{2}}<0.60$ at $1 \mathrm{~h}$ carried $74.1 \%$ specificity, $32.4 \%$ sensitivity, and a negative predictive value of $72.3 \%$ for negative pressure ventilation response. If using $\mathrm{F}_{\mathrm{IO}_{2}}$ at $1 \mathrm{~h}$ to predict negative pressure ventilation failure, the area under the curve-receiver operating characteristic was $0.603,95 \%$ CI $0.490-0.715, P=.08$ (Fig. 2). 


\section{Negative Pressure Ventilation in Pediatric Respiratory Failure}

Table 1. Characteristics for Subjects With Acute Respiratory Failure From Any Cause Supported With Negative Pressure Ventilation

\begin{tabular}{|c|c|c|c|c|}
\hline Variable & All Subjects & $\begin{array}{l}\text { Responded to Negative } \\
\text { Pressure Ventilation }\end{array}$ & $\begin{array}{l}\text { Failed Negative } \\
\text { Pressure Ventilation* }\end{array}$ & $P$ \\
\hline \multicolumn{5}{|l|}{ Demographic variables at admission } \\
\hline Age, months & $12(5.7-21.3)$ & $12(5-20)$ & $14(4-32.5)$ & .38 \\
\hline Male & $71(60.2)$ & $51(63)$ & $20(54.1)$ & .36 \\
\hline Weight, $\mathrm{kg}$ & $9.6(6.9-11.6)$ & $10(7.5-11.6)$ & $9.3(5.9-13.8)$ & .46 \\
\hline PRISM score & $0(0-3)$ & $0(0-2)$ & $3(0-5.3)$ & .01 \\
\hline Acute respiratory failure from bronchiolitis & $102(86.4)$ & $70(86.4)$ & $32(86.5)$ & .99 \\
\hline RSV positive & $51(43.2)$ & $36(44.4)$ & $15(40.5)$ & 69 \\
\hline Chronic lung disease & $13(11.0)$ & $6(7.4)$ & 7 (18.9) & .064 \\
\hline Reactive airways disease & $37(31.3)$ & $27(33.3)$ & $10(27)$ & .28 \\
\hline Upper airway obstruction & $7(5.9)$ & $2(2.5)$ & $5(13.5)$ & .02 \\
\hline Gastroesophageal reflux & $12(10.2)$ & $6(7.4)$ & $6(16.2)$ & .14 \\
\hline Neuromuscular disorder & $3(2.5)$ & $2(2.5)$ & $1(2.7)$ & .94 \\
\hline \multicolumn{5}{|l|}{$\begin{array}{l}\text { Clinical variables } 1 \mathrm{~h} \text { prior to start of negative } \\
\text { pressure ventilation }\end{array}$} \\
\hline Initial venous $\mathrm{pH} \dagger$ & $7.34 \pm 0.08$ & $7.37 \pm 0.05$ & $7.29 \pm 0.09$ & .009 \\
\hline Initial venous $\mathrm{P}_{\mathrm{CO}_{2}}, \mathrm{~mm} \mathrm{Hg} \dagger$ & $44 \pm 9.7$ & $42 \pm 6.6$ & $49 \pm 13.2$ & .066 \\
\hline Heart rate, beats/min & $148 \pm 26$ & $146 \pm 27$ & $154 \pm 23$ & .12 \\
\hline Breathing frequency, breaths/min & $54 \pm 15$ & $55 \pm 14$ & $54 \pm 16$ & .78 \\
\hline $\mathrm{S}_{\mathrm{pO}_{2}}<97 \%$ & $38(32.2)$ & $25(30.9)$ & $13(35.1)$ & .65 \\
\hline $\mathrm{F}_{\mathrm{IO}_{2}}$ & $0.49 \pm 0.23$ & $0.48 \pm 0.20$ & $0.53 \pm 0.27$ & .25 \\
\hline $\mathrm{S}_{\mathrm{pO}_{2}} / \mathrm{F}_{\mathrm{IO}_{2}} \neq$ & $206.7 \pm 87.1$ & $205.9 \pm 87$ & $208.1 \pm 90.9$ & .94 \\
\hline \multicolumn{5}{|l|}{ Outcomes } \\
\hline Pediatric ICU length of stay, $d$ & $3.4(2.2-7.0)$ & $2.5(2-4.1)$ & $10.6(4.7-18.1)$ & $<.001$ \\
\hline Hospital length of stay, $d$ & $5.7(3.8-10.6)$ & $4.8(3.6-7.6)$ & $12.9(7.4-24.2)$ & $<.001$ \\
\hline Hypothermia $\left(<35^{\circ} \mathrm{C}\right)$ & $2(1.7)$ & $2(2.5)$ & 0 & .34 \\
\hline Sedation while on negative pressure ventilation & $94(79.7)$ & $70(86.4)$ & $24(64.9)$ & .007 \\
\hline Delayed enteral nutrition & $44(37.3)$ & $34(42)$ & $10(27)$ & .12 \\
\hline \multicolumn{5}{|c|}{$\begin{array}{l}\text { Data are presented as } n(\%) \text {, median (interquartile range), or mean } \pm \mathrm{SD} \text { where appropriate. All Subjects: } N=118 \text {; Responded to Negative Pressure Ventilation: } n=81 \text { subjects; Failed Negative } \\
\text { Pressure Ventilation: } n=37 \text { subjects. } P \text { values were obtained using chi-square, Mann-Whitney } U \text {, or } t \text { tests where appropriate. } \\
\text { * Defined as requiring other forms of noninvasive ventilation or invasive positive-pressure ventilation. } \\
\dagger \text { Blood gas data only available on } 29 \text { subjects. } \\
\ddagger \text { SF ratio calculated on the } 38 \text { subjects with a } \mathrm{S}_{\mathrm{pO}_{2}}<97 \% \text {. } \\
\text { PRISM = pediatric risk of mortality score }\end{array}$} \\
\hline
\end{tabular}

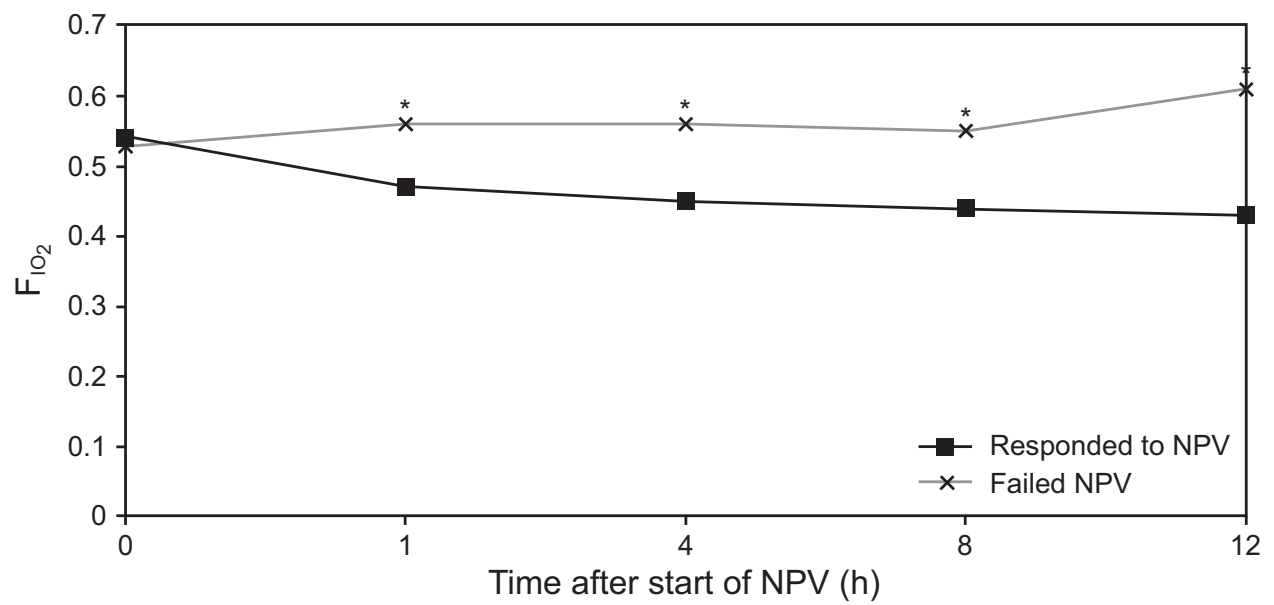

Fig. 1. Trend in mean $\mathrm{F}_{\mathrm{IO}_{2}}$ after start of negative pressure ventilation over time (in hours) in subjects who did and did not require a change in respiratory support. *Differences reached statistical significance as defined by $P<.05$ via independent sample $t$ tests comparing the mean $\mathrm{F}_{\mathrm{IO}_{2}}$ between groups. NPV = negative pressure ventilation. 


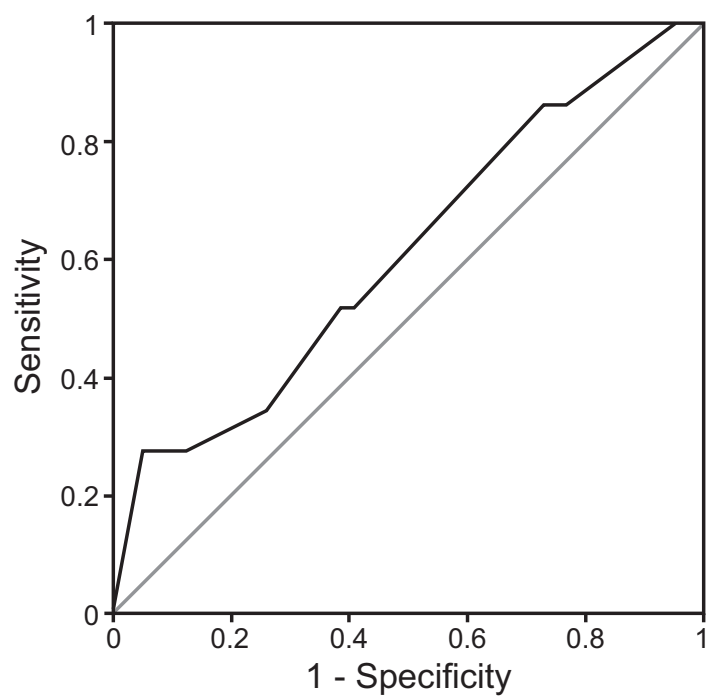

Fig. 2. Receiver-operator characteristic curve to predict negative pressure ventilation response by $\mathrm{F}_{\mathrm{IO}_{2}}$ as supplied by high-flow nasal cannula after the first hour that subjects were supported by negative pressure ventilation. Area under the curve $=0.603,95 \% \mathrm{Cl}$ $0.490-0.715, P=.08$.

Without a $\mathrm{F}_{\mathrm{IO}_{2}}$ weaning protocol, the majority of subjects had a $\mathrm{S}_{\mathrm{pO}_{2}} \geq 97 \%$ at every time point measured. The proportion of subjects with a $\mathrm{S}_{\mathrm{pO}_{2}} \geq 97 \%$ before negative pressure ventilation initiation was $67.8 \%$ (80/118), and this increased to $81.4 \%(96 / 118)$ at $1 \mathrm{~h}$ after starting negative pressure ventilation support. Calculating $\mathrm{S}_{\mathrm{pO}_{2}} / \mathrm{F}_{\mathrm{IO}_{2}}$ only in those subjects with $\mathrm{S}_{\mathrm{pO}_{2}}<97 \%(n=22)$ did show separation between negative pressure ventilation responders $(213.8 \pm 81.8)$ compared to those with negative pressure ventilation failure $(181.9 \pm 80.3)$ at $1 \mathrm{~h}$ after start of negative pressure ventilation; this did not reach statistical significance $(P=.40)$.

Using $\mathrm{S}_{\mathrm{pO}_{2}} / \mathrm{F}_{\mathrm{IO}_{2}}$ at $1 \mathrm{~h}$ to predict negative pressure ventilation response did have better predictive power than $\mathrm{F}_{\mathrm{IO}_{2}}$ at $1 \mathrm{~h}$, area under the curve-receiver operating characteristic $=0.702$ (95\% CI 0.503-0.900, $P=.050)$ (Fig. 3). The optimal coordinate on this curve was $\mathrm{S}_{\mathrm{pO}_{2}} / \mathrm{F}_{\mathrm{IO}_{2}}=192$, with $72 \%$ specificity and $67 \%$ sensitivity for negative pressure ventilation failure with a negative predictive value of $81.8 \%$ for negative pressure ventilation failure. The unadjusted odds of negative pressure ventilation failure in those with $\mathrm{S}_{\mathrm{pO}_{2}} / \mathrm{F}_{\mathrm{IO}_{2}}<192$ at $1 \mathrm{~h}$ was $5.143(95 \% \mathrm{CI} 1.17-22.7$, $P=0.031$ ). After adjusting for age and sex, the odds of negative pressure ventilation failure with $\mathrm{S}_{\mathrm{pO}_{2}} / \mathrm{F}_{\mathrm{IO}_{2}}<192$ at $1 \mathrm{~h}$ was 3.953 (95\% CI 0.844-18.521, $P=.08$ ).

Blood gas data were available for $29(24.5 \%)$ subjects. Subjects responsive to negative pressure ventilation tended to have lower venous $\mathrm{P}_{\mathrm{CO}_{2}}$ values at a baseline $(42 \pm 6.6 \mathrm{~mm} \mathrm{Hg}$ vs $49 \pm 13.2 \mathrm{~mm} \mathrm{Hg}, P=.066)$ and through $8 \mathrm{~h}$ after start of negative pressure ventilation. This difference was significant at $1 \mathrm{~h}$ after initia-

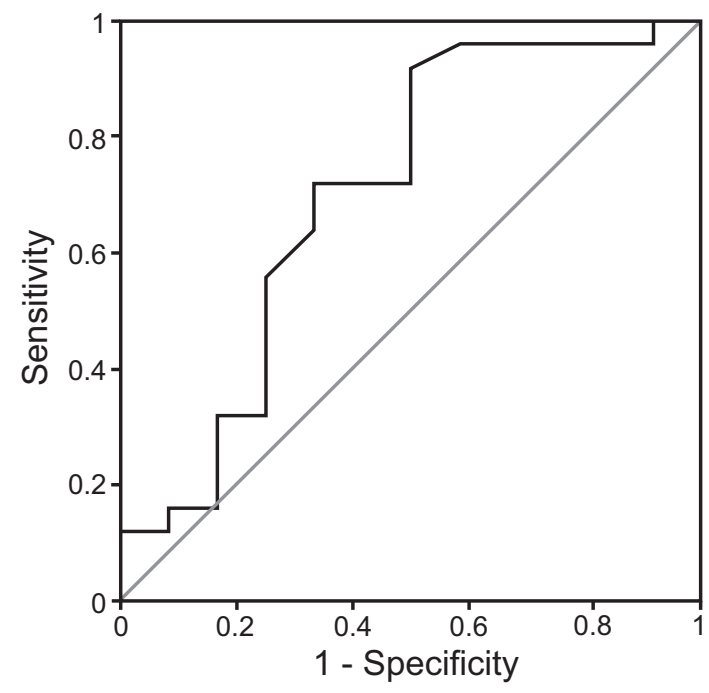

Fig. 3. Receiver-operator characteristic curve to predict response to negative pressure ventilation support by $\mathrm{S}_{\mathrm{pO}_{2}} / \mathrm{F}_{\mathrm{IO}_{2}}$ at 1 hour after start of negative pressure ventilation (including only those subjects with an $\mathrm{S}_{\mathrm{pO}_{2}}<97 \%$ ). Area under the curve $=0.702$, $95 \% \mathrm{Cl} 0.503-0.900, P=.050$.

tion when responsive subjects had a mean venous $\mathrm{P}_{\mathrm{CO}_{2}}$ of $42 \pm 7.4 \mathrm{~mm} \mathrm{Hg}$, whereas those with negative pressure ventilation failure had a mean venous $\mathrm{P}_{\mathrm{CO}_{2}}$ of $55 \pm$ $19.7 \mathrm{~mm} \mathrm{Hg}, P=.03$.

\section{Subgroup Analysis of Subjects With Bronchiolitis}

To determine if certain predictors existed for a more homogenous subject population, we performed a secondary analysis of subjects with bronchiolitis excluding those with a history of upper airway disease $(n=96)$ (Table 2). A larger proportion of subjects with negative pressure ventilation failure $(6 / 29,21 \%)$ had a history of chronic lung disease compared to those who responded to negative pressure ventilation $(4 / 67,6 \%)(P=.030)$. Of the viruses identified, respiratory syncytial virus was the most common $(n=51,53.1 \%)$, followed by human metapneumovirus ( $n=10,10.4 \%$ ). There was no difference in negative pressure ventilation response based on the viral source: respiratory syncytial virus $(P=.69)$, human metapneumovirus $(P=.54)$, adenovirus $(P=.41)$, influenza $(P=.49)$, or parainfluenza $(P=.14)$.

Blood gas data were available for 20 subjects in this secondary analysis: $19.4 \%$ (13/67) of subjects who responded to negative pressure ventilation, and $24.1 \%$ (7/29) of subjects who did not respond to negative pressure ventilation. Mean initial $\mathrm{pH}$ was higher in negative pressure ventilation responders than in non-responders $(7.38 \pm 0.05$ vs $7.33 \pm 0.05$, $P=.042)$. Initial venous $\mathrm{P}_{\mathrm{CO}_{2}}$ tended to be lower in responders, but the difference did not reach statistical significance $(41 \pm 6 \mathrm{~mm} \mathrm{Hg}$ vs $50 \pm 15 \mathrm{~mm} \mathrm{Hg}, P=.062)$. 


\section{Negative Pressure Ventilation in Pediatric Respiratory Failure}

Table 2. Characteristics for Subjects With Acute Respiratory Failure From Viral Bronchiolitis Supported With Negative Pressure Ventilation

\begin{tabular}{|c|c|c|c|}
\hline Variable & $\begin{array}{l}\text { Responded to Negative } \\
\text { Pressure Ventilation }\end{array}$ & $\begin{array}{l}\text { Failed Negative } \\
\text { Pressure Ventilation* }\end{array}$ & $P$ \\
\hline \multicolumn{4}{|l|}{ Demographic variables at admission } \\
\hline Age, mo & $9(5-16)$ & $10.5(5.5-16.3)$ & .60 \\
\hline Male & $43(64)$ & $15(52)$ & .25 \\
\hline Weight, $\mathrm{kg}$ & $9.0(6.9-10.8)$ & $8.9(5.9-10.4)$ & .39 \\
\hline PRISM score & $0(0-2)$ & $0(0-5.5)$ & .11 \\
\hline Chronic lung disease & $4(6)$ & $6(20.7)$ & .030 \\
\hline Days of illness at presentation, $\mathrm{d}$ & $3(2-4.5)$ & $3(2-4)$ & .23 \\
\hline Neuromuscular disorder & $1(1.5)$ & 0 & $>.99$ \\
\hline \multicolumn{4}{|l|}{$\begin{array}{l}\text { Clinical variables } 1 \mathrm{~h} \text { prior to start of } \\
\text { negative pressure ventilation }\end{array}$} \\
\hline Venous $\mathrm{pH} \dagger$ & $7.38 \pm 0.05$ & $7.33 \pm 0.05$ & .042 \\
\hline Venous $\mathrm{P}_{\mathrm{CO}_{2}}, \mathrm{~mm} \mathrm{Hg} \dagger$ & $41 \pm 6$ & $50 \pm 15$ & .062 \\
\hline $\mathrm{S}_{\mathrm{pO}_{2}}<97 \%$ & $17(25.4)$ & $9(31)$ & .57 \\
\hline $\mathrm{F}_{\mathrm{IO}_{2}}$ & $0.46 \pm 0.19$ & $0.49 \pm 0.25$ & .42 \\
\hline $\mathrm{S}_{\mathrm{pO}_{2}} / \mathrm{F}_{\mathrm{IO}_{2}} \neq$ & $245.4 \pm 83$ & $233.9 \pm 81$ & .53 \\
\hline \multicolumn{4}{|l|}{$\begin{array}{c}\text { Clinical variables } 1 \mathrm{~h} \text { after start of } \\
\text { negative pressure ventilation }\end{array}$} \\
\hline Venous $\mathrm{pH} \S$ & $7.36 \pm 0.06$ & $7.31 \pm 0.07$ & .09 \\
\hline Venous $\mathrm{P}_{\mathrm{CO}_{2}}, \mathrm{~mm} \mathrm{Hg} \S$ & $41 \pm 8$ & $53 \pm 20$ & .09 \\
\hline $\mathrm{S}_{\mathrm{pO}_{2}}<97 \%$ & $9(13.4)$ & $5(17.2)$ & .63 \\
\hline $\mathrm{F}_{\mathrm{IO}_{2}}$ & $0.43 \pm 0.15$ & $0.51 \pm 0.22$ & .048 \\
\hline $\mathrm{S}_{\mathrm{pO}_{2}} / \mathrm{F}_{\mathrm{IO}_{2}}$ & $250.4 \pm 78$ & $218.4 \pm 67.4$ & .058 \\
\hline \multicolumn{4}{|c|}{ 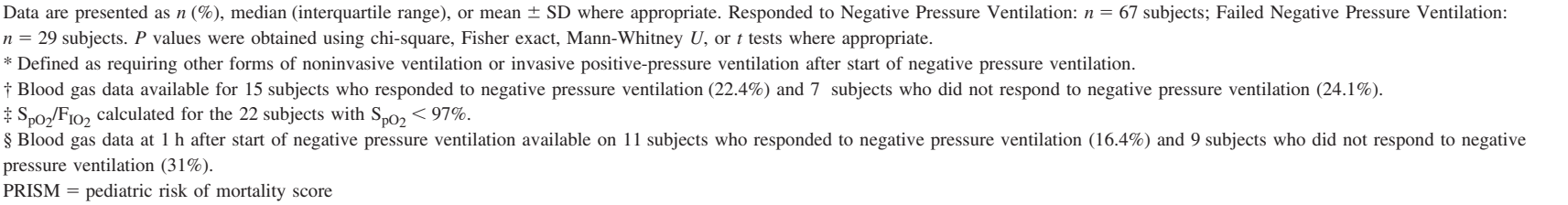 } \\
\hline
\end{tabular}

Initial $\mathrm{F}_{\mathrm{IO}_{2}}$ was similar between the groups but diverged at $1 \mathrm{~h}: 0.43 \pm 0.15$ in those who responded to negative pressure ventilation versus $0.51 \pm 0.22$ in non-responders $(P=.048)$. In bronchiolitis, $\mathrm{F}_{\mathrm{IO}_{2}}$ at $1 \mathrm{~h}$ had fair predictive power for failure of negative pressure ventilation (ie, area under the curve-receiver operating characteristic $=0.612,95 \%$ CI $0.495-0.729, P=.07$ ). With similar baseline values before negative pressure ventilation, the mean $\mathrm{S}_{\mathrm{pO}_{2}} / \mathrm{F}_{\mathrm{IO}_{2}}$ at $1 \mathrm{~h}$ tended to be higher in those who responded to negative pressure ventilation ( 250.4 vs 218.4 , $P=.058)$.

\section{Safety Data}

In all subjects, the complication rate of negative pressure ventilation was $1.7 \%$ (ie, 2 cases of hypothermia in neonates). There were no instances of pneumothorax or breakdown in the skin from the foam ring around the cuirass. There was no reported gastroesophageal reflux or vomiting, including those receiving enteral nutrition while negative pressure ventilation was in place ( 5 subjects were fed by mouth, 3 via gastric tube).
Eighty percent of subjects on negative pressure ventilation support received continuous sedation (dexmedetomidine), with a lower proportion of those with negative pressure ventilation failure receiving sedation. This was likely because of the shorter duration of negative pressure ventilation. There was no difference in the proportion with delayed enteral nutrition between the groups.

\section{Discussion}

Our results show that the majority of pediatric subjects with all-cause acute respiratory failure responded to negative pressure ventilation without a need for intubation or transition to other forms of noninvasive support. The biphasic cuirass ventilator had a low complication rate and a response rate equivalent to other forms of NIV, ${ }^{9}$ with the exception of subjects with upper airway pathology. Because the interface allows for suctioning and oral intake and a rescue rate comparable to other forms of NIV, this modality should be considered a viable option for widespread use. Although we were unable to identify definitive objective predictors of negative pressure ventilation fail- 


\section{Negative Pressure Ventilation in Pediatric Respiratory Failure}

ure using this cohort, our results suggest these predictors exist.

As seen in published HFNC scoring systems that rely heavily on symptoms like retractions, signs of progressing pediatric acute respiratory failure have largely remained subjective. ${ }^{10}$ Our results imply that objective differences could exist if assessments of gas exchange were made more often in children with acute respiratory failure. Even with limited blood gas and $\mathrm{S}_{\mathrm{pO}_{2}} / \mathrm{F}_{\mathrm{IO}_{2}}$ data, there were differences in gas exchange in those responding to and those failing NIV within the first hour of support. These findings are consistent with our previous negative pressure ventilation data ${ }^{5}$ and other NIV studies. ${ }^{911}$ In a large, multicenter trial of 5,847 adults with acute hypoxemic respiratory failure, $\mathrm{P}_{\mathrm{aO}}: \mathrm{F}_{\mathrm{IO}_{2}}<146$ after $1 \mathrm{~h}$ of NIV was associated with 2-fold higher odds of NIV failure (odds ratio 2.51, 95\% CI 1.45-4.35). ${ }^{9}$ In the subset of subjects in whom $\mathrm{S}_{\mathrm{pO}_{2}} / \mathrm{F}_{\mathrm{IO}_{2}}$ was calculable, we found double those odds for children with acute respiratory failure receiving negative pressure ventilation support using $\mathrm{S}_{\mathrm{pO}_{2}} / \mathrm{F}_{\mathrm{IO}_{2}}$ at $1 \mathrm{~h}$. Other studies have reported a failure to reduce the $\mathrm{P}_{\mathrm{aCO}_{2}}$ in $1 \mathrm{~h}$ after NIV start as an important sign of NIV failure. ${ }^{12,13}$ Our limited blood gas data suggest similar is true for pediatric subjects supported by negative pressure ventilation.

Biologic plausibility exists for these findings. NIV, unlike HFNC, augments transpleural pressure to allow recruitment of areas of atelectasis, thus leading to optimal pulmonary blood flow and correction of ventilation/perfusion mismatch. Whether accomplished with positive pressure via face mask or negative pressure on the chest wall, both bilevel positive airway pressure and negative pressure ventilation restore functional residual capacity and improve lung function. As in other pulmonary disease states like ARDS, severity of lung disease is described by surrogates of lung function (ie, gas exchange). If negative pressure ventilation can improve lung function through recruitment, then gas exchange in the form of $\mathrm{S}_{\mathrm{pO}_{2}} / \mathrm{F}_{\mathrm{IO}_{2}}$ and $\mathrm{P}_{\mathrm{CO}_{2}}$ should improve. Our data, like others, indicate that this happens within $1 \mathrm{~h}$ of initiation of support.

Infrequent measurements of $\mathrm{P}_{\mathrm{CO}_{2}}$ and failure to wean supplemental oxygen in the majority of subjects restricted our sample size. Lack of blood gas data were not surprising because serial blood gas measurements are not standard of care in children with bronchiolitis due to its low disease acuity, excellent overall prognosis, and low mortality rate. This is likely why current scoring systems in this disease process remain subjective, as mentioned above. Our findings related to supplemental oxygen have revealed an opportunity for practice improvement that was not apparent at the onset of this study. Although only one fourth of the cohort had blood gas data, an even smaller proportion were weaned with high $\mathrm{S}_{\mathrm{pO}_{2}}$ levels to allow for accurate $\mathrm{S}_{\mathrm{pO}_{2}} / \mathrm{F}_{\mathrm{IO}_{2}}$ calculations. In addition to avoiding unnecessary oxygen exposure, making standardized oxygen weaning protocols could reveal the subset of patients who would benefit from more regular blood gas measurements or earlier escalation of respiratory support. Our results illustrate the ubiquitous practice of supplemental oxygen administration, with our pediatric ICU as an example for other centers. In an era of stewardship and conscious application of therapies to limit morbidity, our dataset emphasizes the importance to assess with reliable markers of clinical status, such as blood gas measurement, and to wean potentially dangerous therapies, such as supplemental oxygen.

Our findings are limited by the retrospective and singlecenter nature of this study. Without set protocols to obtain blood gases or to wean oxygen, clinical behaviors likely created a selection bias. Because $\mathrm{F}_{\mathrm{IO}_{2}}$ was likely to be increased and blood gas data were obtained in sicker subjects, this could have led to an overestimation of the true measure of association. Larger prospective studies with consistent sampling and protocolized weaning of oxygen in subjects supported with negative pressure ventilation are needed to validate these findings.

\section{Conclusions}

Negative pressure ventilation successfully supported $69 \%$ of pediatric subjects with all-cause acute respiratory failure with a complication rate $<2 \%$. Oxygen requirement was lower in subjects who were responsive to negative pressure ventilation within $1 \mathrm{~h}$ of initiation. Standardized protocols for titration of negative pressure ventilation should include weaning of supplemental oxygen and routine blood gas measurements to guide prompt escalation of care.

\section{REFERENCES}

1. Corrado A, Gorini M. Negative pressure ventilation. In: Tobin MJ, editor. Principles and practice of mechanical ventilation, 3rd ed. New York: McGraw-Hill; 2013.

2. Samuels MP, Southall DP. Negative extrathoracic pressure in treatment of respiratory failure in infants and young children. BMJ 1989; 299(6710):1253-1257.

3. Sills JH, Cvetnic WG, Pietz J. Continuous negative pressure in the treatment of infants with pulmonary hypertension and respiratory failure. J Perinat 1989;9:43-48.

4. Shah PS, Ohlsson A, Shah JP. Continuous negative extrathoracic pressure or continuous positive airway pressure compared to conventional ventilation for acute hypoxaemic respiratory failure in children. Cochrane Database Syst Rev 2013;(11):CD003699.

5. Hassinger AB, Breuer RK, Nutty K, Ma CX, Al-Ibrahim OS. Negative pressure ventilation in pediatric acute respiratory failure. Respir Care 2017;62(12):1540-1549.

6. Hull J. The value of non-invasive ventilation. Arch Dis Child 2014; 99(11):1050-1054.

7. Duan J, Han X, Bai L, Zhou L, Huang S. Assessment of heart rate, acidosis, consciousness, oxygenation, and respiratory rate to predict noninvasive ventilation failure in hypoxemic patients. Intens Care Med 2017;43(2):192-199. 


\section{Negative Pressure Ventilation in Pediatric Respiratory Failure}

8. Spada C, Ghandi R, Patel SR, Nuccio P, Weinshouse GL, Lee PS. Oxygen saturation $/ \mathrm{F}_{\mathrm{IO}_{2}}$ ratio is a simple predictor of noninvasive positive pressure ventilation failure in critically ill patients. J Crit Care 2011;26(5):510-516.

9. Antonelli M, Conti G, Moro ML, Esquinas A, Gonzalez-Diaz G, Confalonieri M, et al. Predictors of failure of noninvasive positive pressure ventilation in patients with acute hypoxemic respiratory failure: a multi-center study. Intensive Care Med 2001;27:1718-1728.

10. Chong SL, Teoh OH, Nadkarni N, Yeo JG, Lwin Z, Ong YG, Lee JH. The modified respiratory index score (RIS) guides resource allocation in acute bronchiolitis. Pediatr Pulmonol 2017;52(7):954-961.
11. Evans J, Marlais M, Abrahamson E. Clinical predictors of nasal continuous positive airway pressure requirement in acute bronchiolitis. Pediatr Pulmonol 2012;47(4):381-385.

12. Meduri GU, Abou-Shala N, Fox RC, Jones CB, Leeper KV, Wunderink RG. Noninvasive positive pressure ventilation via face mask: first-line intervention in patients with acute hypercapnic and hypoxemic respiratory failure. Chest 1996;109:179-193.

13. Meduri GU, Abou-Shala N, Fox RC, Jones CB, Leeper KV, Wunderink RG. Noninvasive face mask mechanical ventilation in patients with acute hypercapnic respiratory failure. Chest 1991;100: 445-454. 